\title{
Low socioeconomic class and consumer complexity expectations for new product technology
}

\author{
Carlos A. Trujillo ${ }^{\mathrm{a}, *}$, Andrés Barrios ${ }^{\text {a }}$, Sonia M. Camacho ${ }^{a}$, José Antonio Rosa ${ }^{\mathrm{b}}$ \\ a School of Management, Universidad de los Andes, Calle 21 No. 1-20 SD Building, Bogotá, Colombia \\ b University of Wyoming, Dept. 3275, 1000 E. University Avenue, Laramie, WY 82071, USA
}

\section{A R T I C L E I N F O}

Article history:

Received 1 February 2009

Received in revised form 1 March 2009

Accepted 1 May 2009

\section{Keywords:}

Adoption of new product technology

Complexity expectation

Subsistence markets

\begin{abstract}
A B S T R A C T
This research improves the field's understanding of subsistence consumers by investigating how low socioeconomic class relates to expectations of complexity from new products. The study tests a model of the relationship between consumer socioeconomic class, self-esteem, self-assessed capabilities, and knowledge about product domains, and the influence of self-esteem, self-assessed capabilities, and product domain knowledge on consumer expectations of complexity when facing a new product technology. A sample of 266 Colombian consumers representing different socio-economic classes is used to test the model using structural equation modeling. The results show that self-esteem, self-assessed capabilities, and product domain knowledge are predictive of expectations of complexity, with low self-esteem, low capabilities, and low product knowledge leading to higher complexity expectations. Socioeconomic status relates closely to self-esteem, self-assessed capabilities, and product domain knowledge and can be used as a surrogate for the individual-level constructs.
\end{abstract}

(c) 2009 Elsevier Inc. All rights reserved.

\section{Introduction}

Concurrent with the start of a new century, marketing efforts aimed at base of the pyramid (Prahalad, 2005; Hammond et al., 2007) or subsistence consumers (Viswanathan and Rosa, 2007) have increased substantially. Factors such as aggregate purchasing power in excess of $\$ 5$ trillion contributes to the rising interest, the rapid rate of growth of this newly recognized consumer segment (Hammond et al., 2007), and the promise of substantial revenues and profits to firms with innovative solutions geared toward subsistence consumers (Prahalad, 2005). As many as one billion new subsistence consumers will enter global markets before 2020 (Davis and Stephenson, 2006), leading companies in sectors such as consumer packaged goods, telecommunications, consumer electronics, and financial services to develop and implement marketing strategies to reach such consumers. As with any other market segment, however, subtle differences in consumer needs and capabilities will cause some marketing initiatives to succeed and others to fail, highlighting that marketing practitioners and academicians need to develop a more nuanced understanding of subsistence consumers. This research contributes to such understanding.

Subsistence consumers earn the economic equivalent of less than $\$ 2$ per day, although the actual earnings equivalent to less than $\$ 2$ a day may vary between markets. In all cases, subsistence consumers lack the purchasing power and capabilities to address their own basic needs and those of their families. They typically lack adequate and

\footnotetext{
* Corresponding author.

E-mail addresses: cat@adm.uniandes.edu.co (C.A. Trujillo), abf@adm.uniandes.edu.co (A. Barrios),smc@adm.uniandes.edu.co (S.M. Camacho).
}

consistent access to nutritious food, safe and permanent shelter, health care, and primary education, and limited consumption alternatives (Hammond et al., 2007; Viswanathan and Rosa, 2007). Moreover, these subsistence conditions are relatively stable, giving rise to well-rehearsed consumption strategies often passed to subsequent generations. Subsistence consumers are found in practically all underdeveloped countries and some emergent economies, and are overrepresented in the Indian subcontinent, greater Asia, Latin America, and Africa (Hammond et al., 2007).

Abject poverty aside, subsistence consumers show significant interest and capacity for the adoption of new product and service technologies such as cell phones, consumer electronics, and internet use (see Prahalad, 2005 and Weidner et al., 2010-this issue for examples); technologies that are empowering subsistence consumers and have a significant and seemingly permanent influence on their lives. Cell phones and internet access, for example, are expanding the reach of subsistence consumers who are also farmers and micro-enterprise operators as they search for raw materials and markets for their goods (Prahalad, 2005; Viswanathan and Rosa, 2007), and battery-operated consumer electronics give them access to information and knowledge even in the absence of in-home electricity and running water. In addition, subsistence consumers have shown that marketing initiatives developed for advanced economies may not be suitable for their markets.

Possibly because most subsistence consumers are members of densely networked social and familial communities (Viswanathan et al., 2008), they are comfortable with communal ownership of products such as cell phones and computers which they recharge using communallyowned power sources such as auto batteries (Weidner et al., 2010-this 
issue), and their usage patterns tend to be different from those displayed by consumers in developed economies. Not all marketing initiatives aimed at subsistence consumers have been successful (see Hanson and Powell (2006) for a failed healthcare initiative example), and as the subsistence segment grows and companies invest more resources, marketers need to understand more fully the individual-level particularities of technology adoption in this segment.

This research seeks to combine scientific rigor and pragmatic applicability by assembling into a common framework individual consumer beliefs that influence technology adoption and are also linked to observable characteristics such as socioeconomic class, used here as a surrogate for subsistence status. The primary dependent variable is expectations of complexity, an antecedent of new technology adoption (Rogers, 1996). How product domain knowledge, selfesteem, and self-assessed capabilities relate to expectations of complexity is explored, and reliance on identifiable socioeconomic class as indicative of the individual level constructs is confirmed. The objectives are to better predict subsistence consumer responses to novel product technologies and identify ways to improve marketing efforts. Knowing these effects allows marketers to think beyond income barriers when developing strategies and tactics to reach the poor. In addition, the research contributes to the field's understanding of the technology adoption process by identifying individual consumer differences that companies may face when targeting subsistence segments (see Venkatesh et al. (2007), for a recent review of the new directions of research on technology adoption). Finally, by involving subsistence and nonsubsistence consumers (different socioeconomic classes) the study allows a clear comparison of differences.

The paper next presents the theoretical justification for product domain knowledge, self-esteem, and self-assessed capabilities being related to socioeconomic class and predictive of expectations of complexity is presented, leading to a conceptual framework and related hypotheses. Next, the paper discusses the details of a quasiexperimental study that test the framework. Then the paper presents the results of the analysis using structural equation modeling. Results show that the scheme is an adequate representation of how socioeconomic class relates to expectations of complexity, and provides insights on the mechanisms involved. Finally, the paper concludes with theoretical and managerial implications from the research.

\section{Theoretical background}

\subsection{Complexity expectations and technology adoption}

The set of mental and behavioral processes that precede actual adoption is an interesting aspect of technology (e.g., Bruner and Kumar, 2005; Davis et al., 1989). From among these processes, this research focuses on the expectations of complexity that consumers develop when facing new product technologies. Putting aside the objective degree of complexity inherent in all new product technologies, this research focuses on perceived complexity, defined as the "degree to which an innovation is perceived [by the consumer] as relatively difficult to understand and use" (Al-Gahtani, 2003, p. 60). Such perception arises from consumers' ex-ante predictions about ease of use, learning time, and learning difficulty of new products (Wood and Moreau, 2006). Perceived complexity is important to the diffusion of innovation (Rogers, 1996), and research shows that perceived complexity has a negative influence on the adoption of new technologies (e.g., Tornatzky and Klein, 1982; Al-Gahtani, 2003). Moreover, how complex consumers expect a product to be constitutes a barrier to actually adopting new technologies (e.g. Shih and Venkatesh, 2004; Thompson et al., 2005; Wood and Moreau, 2006).

A number of variables that affect technology adoption (see Rogers, 1996) may relate to consumer socioeconomic class. Among them, expectations of complexity stand out because they arise from consumers' subjective assessments and the resulting emotions, and may consequently be related to other beliefs held by subsistence consumers, beliefs that may be at least partially caused by life conditions common to a socioeconomic class (e.g., subsistence and nonsubsistence). Studying the relationship of socioeconomic class, intervening beliefs, and expectations of complexity can provide insights into mental factors that get in the way of subsistence consumers acceptance of new technologies.

\subsection{Complexity expectations, socioeconomic class and subsistence consumers}

Although the negative influence of expected complexity on the adoption of new technologies has been confirmed by multiple studies (e.g., Shih and Venkatesh, 2004; Thompson et al., 2005; Wood and Moreau, 2006), little research examines variables that may shape such expectations. Complexity expectations should be studied from the perspective of the consumer and not the product because they are subjective. In particular, the analysis should focus on characteristics of the consumer context that are related to complexity, such as the levels of education, income, and living conditions, factors often associated with a consumer's socioeconomic class (Hollingshead and Redlich, 1967). Socioeconomic conditions provide a specific context under which consumers develop beliefs and associated emotions about the complexity of new technologies, and insights into such beliefs advance the field's understanding of barriers to subsistence consumer adoption of new product technologies.

Complexity expectations relate to consumer-held beliefs about their relationship to existing and new product concepts, and the consumer's context affects such beliefs. The consumers' market context serves as a framework for the development of their cognitions, emotions and intentions (Hill and Gaines, 2007), revealing a connection between their sense of self and the ability to consume (McCracken, 1986; Zukin and Maguire, 2004). Further, socioeconomic class shapes individual differences within market context (Boardman and Robert, 2000; Wheatley et al.,1980). Consumers' socioeconomic class shapes their beliefs, attitudes and behaviors (Lewis, 1959; Hill and Stephens, 1997; Jones and Ye, 1999) and is correlated to the consumer's consumption behaviors (Coleman, 1983; Levy, 1966; Schaninger, 1981). Arguably, socioeconomic class is associated to different levels of complexity expectations, that part of the association stems from beliefs held by consumers that are shaped by socioeconomic class, and that such beliefs influence complexity expectations. Consumer socioeconomic class is thus expected to be correlated to consumer beliefs about the self and product domain knowledge, and such beliefs and knowledge in turn give rise to expected complexity when consumers confront a new product or technology. The following sections provide specific hypotheses on the nature of these relationships.

\subsection{Factors affecting complexity expectations}

Past research into consumer adoption of new products has identified variables related to both expectations of complexity and socioeconomic class. Three variables were selected based on recent advancements in the area: First, product knowledge - the information a consumer retrieves when encountering a new product by associating it to a primary or supplementary product category (Moreau et al., 2001a,b). Second, subjective beliefs of capabilities consumers' judgments on their general own skills and capabilities (Beloff, 1992). Third, self-esteem or the subjective perception of one's worth (Blascovich and Tomaka, 1991; Twenge and Campbell, 2002).

\subsubsection{Complexity expectations and knowledge}

The cognitive side of expectations is related to consumer knowledge. Bettman and Park (1980) stressed the role of pre-existing knowledge in the formation of expectations, pointing out that consumers make sense of new product information by mapping such 
information against their past and present experiences. The mapping process contributes to expectations about the new product. Other research affirms the mapping perspective, stating that complexity expectations are constructed from the consumer's relevant prior knowledge (Oliver and Winter, 1987; Wood and Moreau, 2006). The knowledge involved stems from previous experiences and lacks a specified category structure.

Previous research (Moreau et al., 2001b) further established that when consumers encounter new products (e.g., an electronic book device), their pre-existing knowledge may be parsed into category domains that are partially informed by the new device, often into a primary domain that is directly associated with the new product (e.g., an electronic tablet) and a supplementary or secondary domain salient novel attributes of the new product have been noted (e.g., personal digital assistant). The process of knowledge parsing and category association facilitates product learning (Gregan-Paxton and John, 1997) by allowing the consumer to transfer extant knowledge from familiar to novel domains (Yamauchi and Markman, 2000). Furthermore, marketers may facilitate categorization-based transfer of knowledge by giving consumers a plausible category label, although the primed category may modify consumers' expectations of product features (Moreau et al., 2001b). This study explores the notion that consumer knowledge of products that are already available in the market reduces expectations of complexity, possibly because being able to associate new products to existing categories provides coherent representations of how new products should be used. Even if the representations ultimately prove false, being able to project how the new product may be used reduces expectations of complexity. These arguments lead to the formulation of the following hypothesis:

H1. Expectations of complexity decrease as knowledge of product domains increases.

The same product must be used in the study to rule out effects of particular complexity of category domains (i.e., specific categories may be more complex than others).

\subsubsection{Complexity expectations and self-assessed capabilities}

Past research has not explored the connection between consumers' beliefs about their own capabilities and their complexity expectations, expecting a relationship to exist and self-assessed capabilities to influence complexity expectations about new products is reasonable. Higher self-assessed capabilities should result in lower expected complexity, based on the notion that a general sense of one's own capabilities is likely to shape expectations for the difficulty or ease of any specific task a person faces. This argument is consistent with perceived self-efficacy being a regulator of cognitive processes (e.g., Bandura, 1989; Gist and Mitchell, 1992). Self-efficacy and self-assessed capabilities are closely aligned constructs (Bandura,1997). Hence, self-assessed capabilities are assessments of self-efficacy in areas where consumers perform day-to-day activities like buying and using products. For instance, purchasing products requires arithmetic, verbal and interpersonal skills. Similarly, spatial and linguistic intelligence are required to understand how products work and to envision their use. Expectations about learning and usage of products are components of perceived complexity, and consumer's general assessment of her capacities will influence how difficult or easy using a new product will appear. Consumers with high self-assessed capabilities will hold low expectations of complexity for new products and be more willing to try them than consumers with low self-assessed capabilities. More formally:

H2. Expectations of complexity decrease as self-assessed capabilities increase.

In addition, lower socioeconomic class consumers (i.e., subsistence consumers) are expected to display lower self-assessed capabilities and higher expectations of complexity for new products, given that lower socioeconomic classes often have lower self-assessments of capabilities (Lewis, 1959; Hill and Stephens, 1997; Jones and Ye, 1999).

\subsubsection{Self-esteem and complexity expectations}

Similar to self-assessed capabilities, past research has not explored the relationship between self-esteem and complexity expectations, where self-esteem is seen as a sense of self-worth (Blascovich and Tomaka, 1991). This is in contrast to self-efficacy, which is concerned with perceived personal capability as it pertains to tasks (Bandura, 1997). Self-esteem is also associated to socioeconomic class (Twenge and Campbell, 2002), with higher socioeconomic class leading to higher self-esteem. In addition, the closer consumers are to subsistence conditions, the greater the influence of self-esteem because of how social stigma affects consumer self-esteem (Adkins and Ozanne, 2005). Subsistence conditions are often associated with stigmatization, particularly in societies with wide dispersion in living standards and where consumers are highly aware of their social classification.

Self-esteem is related to self-efficacy (Bandura, 1997). They are distinct and associated factors that impinge on individuals who are trying to do well in any given pursuit. No fixed mechanism links how much one likes oneself to beliefs regarding one's capabilities, but Bandura (1997, p. 11) argues that the correlation between them increases when they are measured concurrently in the context of activities where the individual invests his or her sense of self-worth; activities such as evaluating new products for possible consumption. Consumers facing new product concepts are likely to generate coping responses that are informed by their self-assessed capabilities and self-esteem. More specifically:

H3. Self-esteem is positively associated with self-assessed capabilities in the context of new technology products.

Because self-esteem focuses on self worth and is not task specific, however, self-esteem is not expected to affect complexity expectations directly, but to show, as hypothesized, a strong positive correlation to self-assessed capabilities and no direct influence on complexity expectations. The next section explains how these antecedents to complexity expectations relate to socioeconomic class.

\subsection{Socioeconomic class and consumer-level constructs}

This section discusses the relationship between socioeconomic class and the consumer-level constructs discussed in the previous sections, (i.e., consumer product domain knowledge, self-assessed capabilities, and self-esteem). The section treats socioeconomic class as arising from the co-occurrence of factors such as income, education, area of residence, and parents' education. To understand subsistence consumers researchers should take into account such variables in addition to income. This is because subsistence conditions are relatively stable for many consumers on account of low levels of education, compromised housing in marginal areas, and family traditions and values that make it difficult for consumers to overcome subsistence living conditions. No single factor from the list above causes subsistence conditions, nor does addressing any single one provide a way out. Consequently, this research does not explore the effects of the variables separately, but follows instead the conceptual approach of Hollingshead and Redlich (1967); measuring each factor individually (i.e., income, education, residential area and parents' education) and treating them as reflective of a latent socioeconomic class construct.

\subsubsection{Socioeconomic class and self-esteem}

Twenge and Campbell (2002) found a significant positive relationship between self-esteem and socioeconomic class, emphasizing that income, education and occupation were the most salient aspects of socioeconomic class that drive self-esteem. The conceptual treatment 


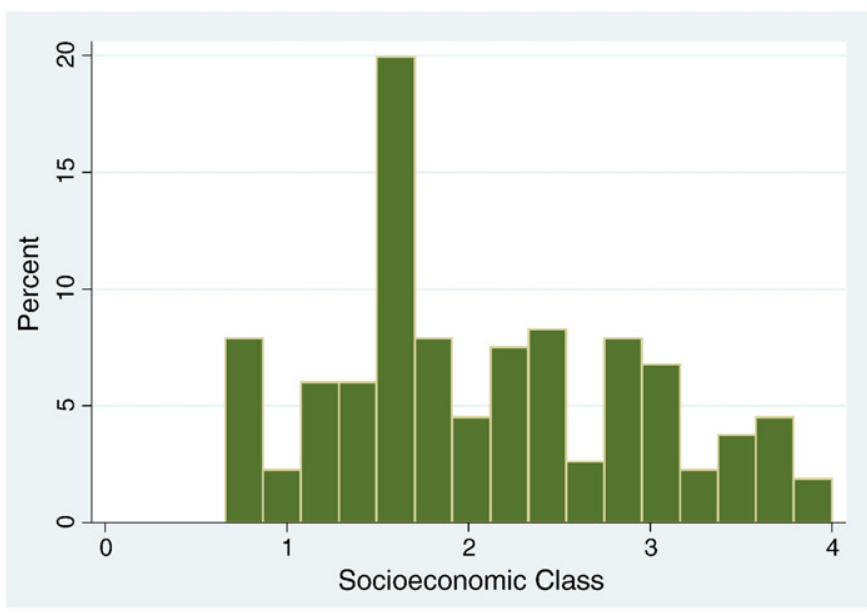

Fig. 1. Distribution of sample socioeconomic class.

of socioeconomic class in this research fits Twenge and Campbell's (2002) treatment, and socio-economic class is expected to correlate positively to self-esteem, so that low socioeconomic class is associated to low selfesteem.

H4a. Socioeconomic class is positively correlated to self-esteem.

\subsubsection{Socioeconomic class and product knowledge}

Subsistence consumers have been characterized as uneducated and with limited experience in important areas of social interaction, causing a type of exclusion of such consumers from marketing activities (Alwitt and Donley, 1996; Bauman, 1988; Boyce, 2000; Hamilton and Catterall, 2005). Their isolation attenuates subsistence consumer knowledge about new products. Subsistence consumers are targeted less often by marketing initiatives that disseminate product information (i.e., advertising, promotions), and are consequently less likely to hold product domain knowledge about many categories. Although researchers have not explicitly established a direct relationship between socioeconomic class and product domain knowledge, prior knowledge about products is known to stem from exposure to external sources of information (Gregan-Paxton and John, 1997). Because being in a low socioeconomic class typically involves having lower exposure to the marketing activities that educate consumers in the capabilities and functions of products, they are expected to know less about product domains. Socioeconomic class is expected to be negatively related to knowledge of product domains, with subsistence consumers knowing less about product domains than more affluent consumers, leading to the following hypothesis:

H4b. Socioeconomic class is positively correlated to knowledge of product domains.

\subsubsection{Socioeconomic class and self-assessed capabilities}

The relationship between socioeconomic class and self-assessed capabilities can be derived from several sources. Alwitt and Donley (1996), for example, describe societies where subsistence consumers

Table 1

Composition of the six strata in Bogotá population.

\begin{tabular}{llcc}
\hline $\begin{array}{l}\text { Residential } \\
\text { stratum }\end{array}$ & Description & $\begin{array}{l}\text { Percentage of } \\
\text { population (\%) }\end{array}$ & $\begin{array}{l}\text { Average monthly income } \\
\text { by household 2006 (US\$) }\end{array}$ \\
\hline 1 & Low-low & 8 & 350 \\
2 & Low & 36 & 460 \\
3 & Medium-low & 40 & 800 \\
4 & Medium & 10 & 1780 \\
5 & Medium-high & 6 & 2740 \\
6 & High & & 3470 \\
\hline
\end{tabular}

a The exchange rate is 1 dollar $=2506$ Colombian pesos (January 2009). are expected to underperform on intellectual tasks, and some studies find a stereotypical view of poverty, in the sense that poverty is caused by a lack of capabilities (Becker, 1997). In addition, conceptions about low socioeconomic class groups can be strong enough to produce a stereotype or stigma that is often also adopted by the poor (e.g., Croizet and Claire, 1998; Rist, 1970). Subsistence consumers seeing themselves as having low capabilities leads them to underperform in a variety of tasks (Crocker and Major, 1989; Steele, 1997) and to lower self-assessments of intelligence (Beloff, 1992). The aggregated evidence suggests that subsistence consumers may see themselves as low in self-efficacy when faced by new product technologies, and that low socioeconomic status will be associated with low selfassessed capabilities.

H4c. Socioeconomic class is positively correlated to self-assessed capabilities.

\section{Test of the conceptual scheme}

The hypothesized relationships were tested using a quasi-experimental procedure that varies socioeconomic class through sampling, and the data were analyzed using structural equation modeling. The model operationalizes all the relationships and hypotheses discussed so far.

Particular attention should be paid to the measurement model of socioeconomic class. Socioeconomic status has been traditionally modeled as formative (Viswanathan, 2005), based on the argument that socioeconomic status comes about (e.g., is formed) as a result of factors such as income and education. For purposes of this research, however, a distinction between socioeconomic status as described above and socioeconomic class, as a mental model adopted by consumers about themselves and others that informs their behaviors and expectations must be made. When it comes to socioeconomic status, the "formed" conceptualization suggests that individuals can alter their status through changes to some of the formative elements, such as increasing their income or attending a university. This view ignores, however, the fact that the socioeconomic class into which a person is born, recognized through external cues such as last name, city of birth, and experiences on the path to adulthood, can have a significant influence on self image and how others treat the individual even in the face of achieved high income and levels of education. This state of affairs, for example, keeps scavengers at the bottom of the socioeconomic class hierarchy in many subsistence markets, even when they sometimes earn ten times the national minimum wage (see

Table 2

Construct reliability coefficients.

\begin{tabular}{lll}
\hline Construct & Variable & Cronbach's alpha \\
\hline SEC & Educational scale & .87 \\
& Residential area & \\
& Monthly income & \\
& Parents' educational scale & .65 \\
Self-esteem & General & \\
& School & \\
& Peers & .89 \\
Expectations of complexity & Home & \\
& Product challenge & \\
& Product learning time & \\
& Product difficulty & \\
& Task challenge & .76 \\
& Task learning time & \\
& Task difficulty & \\
Capabilities & Spatial intelligence & \\
& Linguistic ability & \\
& Arithmetic ability & \\
& Verbal fluency & \\
& Interpersonal intelligence & \\
& PDA knowledge & \\
Product knowledge & E-book reader knowledge & \\
&
\end{tabular}


Medina (2007) for examples). When it comes to attitudes toward self and new technologies among subsistence consumers, their selfassigned socioeconomic class will have bearing where they live and how much education they pursue, and on their approach to new products. It would take more than a change in domicile or educational level to alter the consumer's socioeconomic class as a mental model and its influence on the adoption of new product technologies, leading to the construct being modeled as reflective for purposes of this study.

To perform the quasi experimental task, consumer participants were recruited from an array of socioeconomic classes in Bogotá, Colombia. They were individually exposed to a new product technology and asked to envision a task related to the technology. Data for all variables were gathered during a single session.

\subsection{Sample}

A professional market research firm was used to recruit 266 participants from Bogotá, Colombia, representing the city's socioeconomic strata. Bogotá was chosen because of its ready access to global consumer markets and a well educated and affluent high class. It also has a significantly-sized subsistence consumer population. Local government estimates that as much as $40 \%$ of the city's 8.5 million consumers live in subsistence conditions. Participants were recruited in their neighborhoods, and traveled to a neutral location in small groups to participate in the study. Average age is 39 years old, with a standard deviation of 16 years, ranging from 19 to 84 years, and $50.8 \%$ of participants were male. Socio-economic class was captured through the aggregation of four items, income, education, area of residence, and parents' education. These are the four reflective indicators of socioeconomic class as explained above. The sample reflecting the socioeconomic distribution in the city was confirmed by creating a socioeconomic composite score for each participant and comparing the distribution of such scores against the city's class demographics. The resulting distribution is illustrated in Fig. 1. In general the sample matches Bogotá's social class distribution, with an over-representation of low-middle and low class consumers. Government estimates place the proportion of subsistence consumers at $40 \%$, which is in line with the representation of social classes achieved by the sample.

\subsection{Procedure}

The quasi-experimental procedure was performed in a private office, one participant at a time. Only one researcher was present. The procedure consisted of four phases. First, respondent socioeconomic class was determined. Second, participants completed a series of instruments regarding self-esteem, self-assessed capabilities and knowledge of technology domains. Third, participants were introduced to the new product and asked to envision using it. Finally, the participants were asked to complete the expectations of complexity questionnaire. Before leaving, participants were paid a flat fee of 6, 9 or 14 USD based on their socioeconomic class.

\subsubsection{Choice of new product stimulus}

The choice of new product stimulus was based on two requirements: not be available in the local market (so most participants would not know how to use it) and be associated to either a primary or supplemental product domain. Meeting these conditions helped ensure that the stimulus was a truly new product, and that the measures of product knowledge domains would yield data consistent with the adopted definition of product knowledge. Pretests of several products were conducted with 180 participants from different socioeconomic classes in Bogotá, chosen through the same procedure as for the main sample. Participants were exposed to photos and information about three products, an e-book (also known as Kindle), a digital USB photo frame, and a GPS (Global Positioning System) portable device. Participants were asked how much they knew about the product and in what

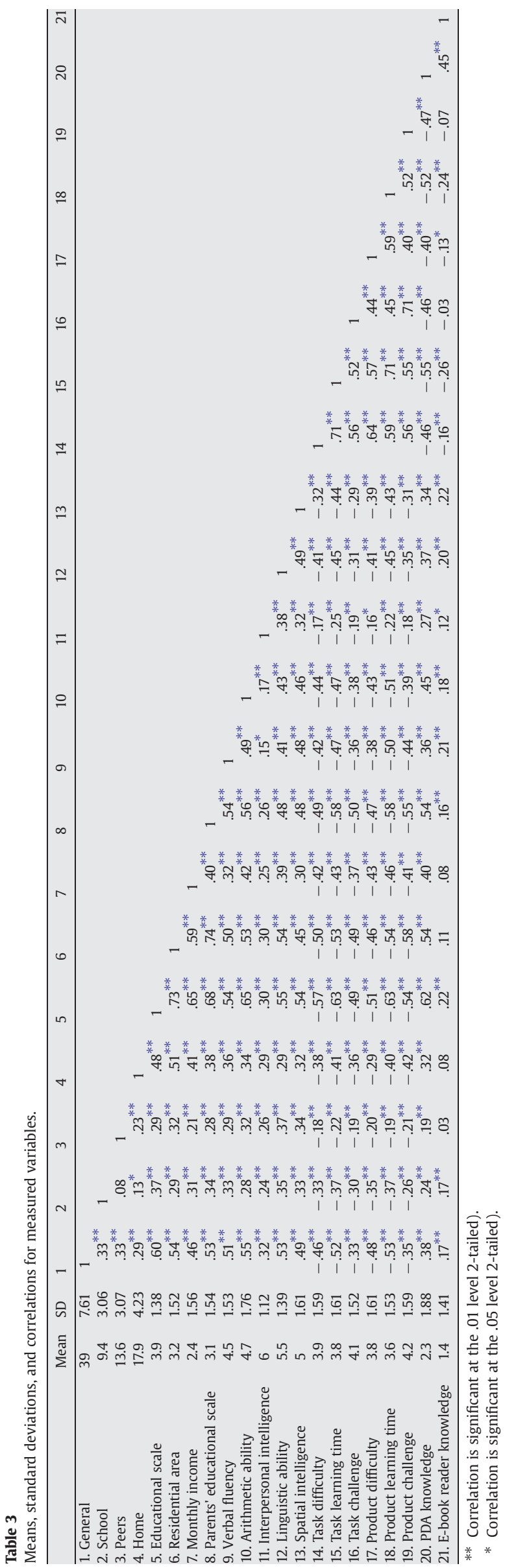


category they would place the product. The least known product that could nevertheless be assigned to a primary or supplemental category was the e-book. The primary category most used by participants for the e-book was "digital book reader" (31\%); and the most frequently used supplemental category was PDA (personal digital assistant) (46\%).

\subsubsection{Measurement instruments}

Socioeconomic class was captured through demographic information. An approach similar to that of Hollingshead and Redlich (1967) was used, where socioeconomic class can be determined using a few symbolic characteristics that denote a latent social class. Hollingshead and
Redlich (1967) used residential area, educational level and occupation. This study substituted income for occupation and added parents' educational level. The former was modified because subsistence consumers in Bogotá operate microenterprises that fall outside typical occupational categories. Parent's education was introduced under the belief that low socioeconomic class is a relatively stable condition where the class of parents curtails opportunities for children to move up or down social levels. People whose parents are poorly educated are hence more likely to also be poorly educated and not rise socially, and those with well educated parents are less likely to drop even if they do not attain high levels of education. Personal income and educational levels

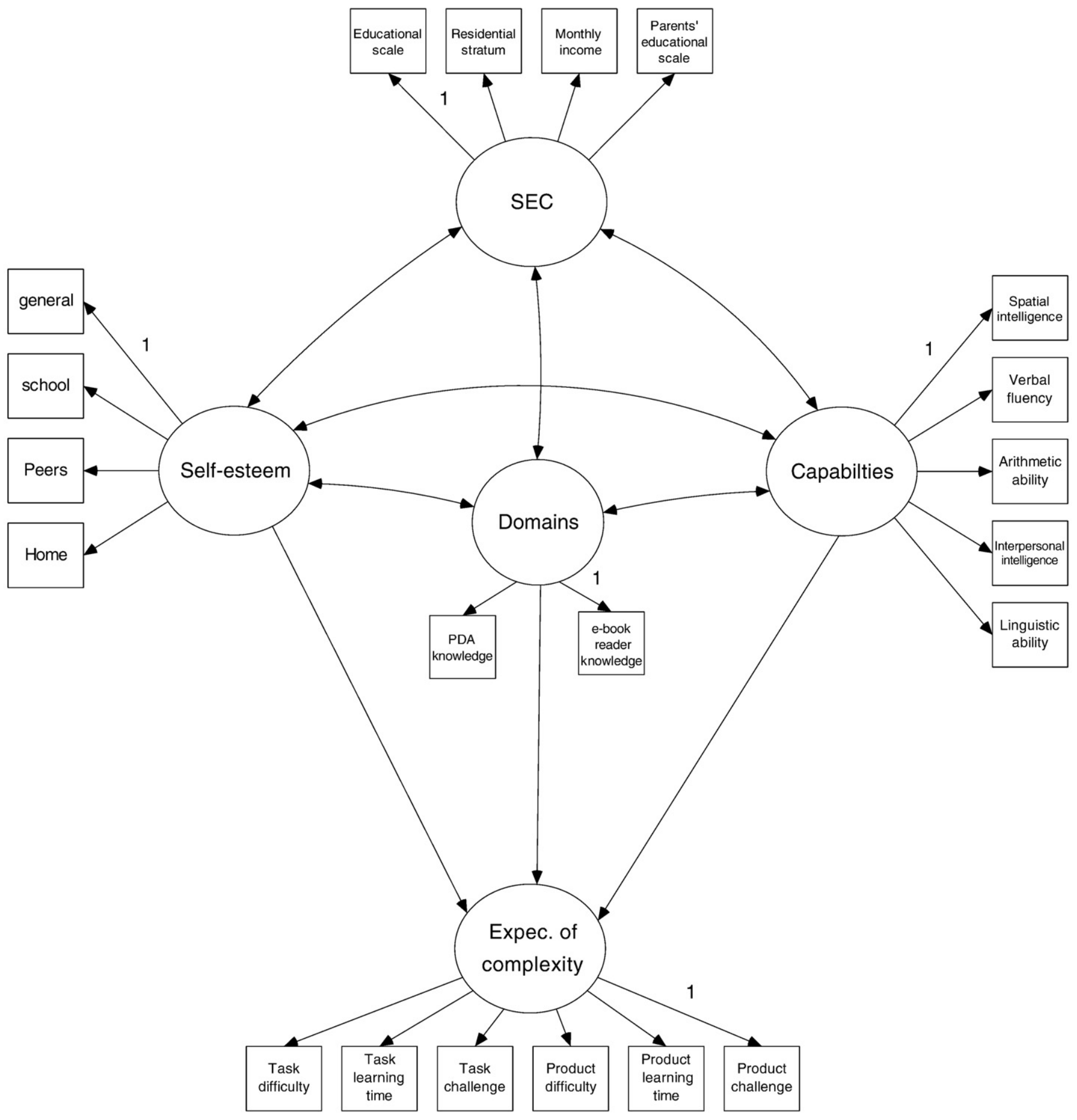

Fig. 2. Path diagram of the relationship between socioeconomic class and expectations of complexity. 
were captured using six-point categorical scales. Residential area was captured by utilities tariff categories established by Bogotá's municipal government; a 1-6 classification system where one is the poorest stratum and six is the wealthiest stratum. Practically all Bogotá residents know their residential area classification because of its multiple uses. Table 1 shows the composition of the six strata in Bogota's population. Details on Bogotá's utilities stratification scheme and scales used for income and education are included in Appendix A.

Self-esteem was captured using the Coopersmith Self-Esteem Inventory (1967). This test consists of 25 questions that evaluate participants' self worth perceptions in four areas: (1) social self-peers, (2) home-parents, (3) school/work (4) general-self. The Spanish validated version of the instrument (Lara-Cantú et al., 1993) was used. Because of the risk of under specifying of the model that the use of 25 measurement variables entails with a sample size of 266, parceling (Hall et al., 1999) of the 25 variables was performed. The 25 items are grouped for estimation purposes in line with Coopersmith (1967) definition of the four underlying dimensions of self-esteem: general, school, peers, and home. Knowing that an empirically-confirmed factor structure justifies parceling a large number of measurement items and reduces the need for cross-loadings among indicators during the structural estimation procedure (Hall et al., 1999).

For self-assessed capabilities the methodology used by Rammstedt and Rammsayer (2002) was adapted. Rammstedt and Rammsayer asked people to evaluate themselves in the seven aspects of intelligence (verbal comprehension, verbal fluency, arithmetic ability, memory, perceptual speed, inductive reasoning and spatial visualization), and on the types of intelligence proposed by Gardner (1983): linguistic, logicalmathematical, spatial, musical, body-kinesthetic, interpersonal and intrapersonal intelligence. The original questionnaire was too difficult for low socioeconomic class participants and too long for the current study, leading to an item subrogation of the original scale - reducing the original test to its main items. The instrument was administered to 64 subjects who did not participate in the main study and factor analysis was used to determine which of the 14 original items should be included. In line with Hair et al. (1998) only those items with a factor loading of .7 or above in each factor of the rotated solution were used. They are verbal fluency, arithmetic ability, interpersonal intelligence, linguistic intelligence and spatial intelligence. Participants were asked to self-evaluate on each item using a seven point scale.

Participants' knowledge of product domains was measured using two questionnaires composed of six true/false statements, one questionnaire for each category domain: digital book reader (primary) and PDA (supplementary). Participants assessed if statements were true or false. 'Do not know' was included as an optional response to avoid guessing (Johar et al., 1997; Moreau et al., 2001a). The sum of the correct answers in each domain provided the measure of knowledge. Expectations of complexity were captured following Wood and Moreau (2006) and Rogers (1996). Participants indicated their perceived difficulty regarding both understanding the product itself and using it. Three aspects are measured for both product and task: learning difficulty, perceived challenge and overall perceived difficulty. For each aspect, participants answered using a seven point scale. This provides a total of six measures for the expectations of complexity construct.

All variables included in the model were reliably measured. Reliability coefficients are reported in Table 2 and correlations between measurement variables are reported in Table 3.

\subsection{The structural model}

The proposed relationships are tested using structural equation modeling because the endogenous/exogenous nature of consumer beliefs is best captured by the simultaneous estimation of their correlation with socioeconomic class and influence on complexity expectations. Fig. 2 shows the measurement and structural models being tested.
Modeling covariation between socioeconomic class and self-esteem, self-assessed capabilities and product domain knowledge supports the idea that socioeconomic class is strongly associated with such beliefs. Being a subsistence consumer (low socioeconomic class) implies poor knowledge of products, low self-esteem and low perception of one's abilities, when compared to consumers in higher socioeconomic classes. Similarly, the covariation of self-esteem and self-assessed capabilities supports their strong conceptual relationship. The arrows from selfesteem and product domain knowledge to expectations of complexity are single-headed, denoting the hypothesized causal relationships.

\section{Results}

A maximum likelihood algorithm was used to estimate the hypothesized relationships illustrated in Fig. 2. All measurement variable loadings are significant, affirming the convergent validity of the constructs. Overall model fit is also encouraging. Although the $\chi^{2}$ goodness of fit statistic is significant $\left(\chi^{2}=259.7, d f=157, p<.000\right)$, a combination of absolute and relative fit indices suggests that the modeled relationships are adequately supported by the data (Hu and Bentler, 1999). The model produced a comparative fit index (CFI) of .97 , root mean square error of approximation (RMSEA) of .050 and a Tucker Lewis index (TLI) of .95. In addition, the squared multiple correlation of expectations of complexity was .67, meaning that the model captured $67 \%$ of this construct's variance. Given its complexity and sample size $(n=266)$, the model shows a good fit based on established criteria for model acceptance (Hu and Bentler, 1999; Marsh et al., 2004; Hair et al., 1998; Carmines and McIver, 1981; Browne and Robert, 1993).

All hypothesized relationships are supported. Product domain knowledge $(\gamma=-.48, p<.02)$ and self-assessed capabilities $(\gamma=-.51$, $p<.00$ ) have a negative influence on expectations of complexity, supporting $\mathrm{H} 1$ and $\mathrm{H} 2$, and a significant covariance between self-esteem and self-assessed capabilities is found $(\varphi=6.06, p<.00)$ in support of H3. Pertaining to relationships between socioeconomic class and selfesteem, knowledge and self-assessed capabilities, those hypotheses (H4a, H4b and H4c) are also supported. The covariance of socioeconomic class with self-esteem is $(\varphi=6.30, p<.00)$, the covariance of socioeconomic class with product domain knowledge is $(\varphi=.329, p<.00)$, and the covariance of socioeconomic class with self-assessed capabilities is $(\varphi=1.20, p<.00)$ are all significant and in the expected direction. Finally no evidence exists of a direct effect of self-esteem on complexity expectations. Table 4 shows path estimates for the structural model and Table 5 shows estimates for the measurement model.

\section{Discussion}

This research develops and tests a model which shows that individual-level beliefs influence consumer expectations of complexity when encountering new products. Concurrently, the research shows that those individual level beliefs are correlated to socioeconomic class, making it feasible to use consumer socioeconomic class as a surrogate for individual-level beliefs that inform complexity expectations, and possibly influence consumer adoption of new product technologies. At a practical level the research also shows that low socioeconomic class consumers are less likely to adopt new product technologies when compared to higher socioeconomic class consumers because of different beliefs they hold about their self worth and capabilities, and their different levels of knowledge of product domains. The research has theoretical and managerial implications.

\subsection{Theoretical implications}

Innovative marketing strategies aimed at entering emerging markets must take into account the psychological aspects of the subsistence consumer (Sridharan and Viswanathan, 2008), and this study 
contributes to the field's grasp of how product knowledge, self-esteem, and self-assessed capabilities shape consumer responses to new products. Finding that such factors influence complexity expectations affirms the argument that subsistence consumers face barriers that go beyond income and literacy problems when adopting new technologies (Sridharan and Viswanathan, 2008). The findings from this study provide insights on some psychographic characteristics of subsistence consumers that influence their technology adoption process.

The research also shows that socioeconomic class is a contextual variable correlated with consumer beliefs about themselves and knowledge of existing product domains which may indirectly influence consumer expectations of complexity when they encounter new products. Previous research has explored cognitive and affective links to technology adoption (e.g., Wood and Moreau, 2006; Kulviwat et al., 2007). The present work extends this knowledge by offering a theoretical grounded and empirically confirmed explanation of the link between one salient consumer characteristic (i.e., socioeconomic class) and individual-level influencers of new product adoption (i.e. expectations of complexity).

The research confirms the influence of product domain knowledge on the technology adoption process (Gregan-Paxton and John, 1997; Moreau et al., 2001b; Gregan-Paxton, 1999; Yamauchi and Markman, 2000), and provides evidence of a relationship between consumer knowledge of product domains and socioeconomic class. From a marketing perspective, finding this two-way link makes salient the consequences of what some researchers (e.g., Alwitt and Donley, 1996; Also, Hamilton and Catterall, 2005; Boyce, 2000) called the exclusion of low income consumers from some marketing strategies. Such exclusion creates market and intellectual barriers that require time and additional research to be properly overcome.

Finally, the operationalization of socioeconomic class in this research, as a latent variable reflected by income, education, area of residence, and parent's education, provides a more holistic characterization of subsistence and nonsubsistence conditions than reliance on single factors such as income or literacy skills, while at the same time remaining tractable and accessible to academic and practicing researchers. Both literacy and income are salient aspects of subsistence conditions and their combination with residential area and parents' educational level ensures a more accurate classification of subsistence consumers.

Table 4

Estimates of the structural model.

\begin{tabular}{|c|c|c|c|c|}
\hline Structural model & $\begin{array}{l}\text { Standardized } \\
\text { coefficients }\end{array}$ & $\begin{array}{l}\text { Unstandardized } \\
\text { coefficients }\end{array}$ & $\begin{array}{l}\text { Standard } \\
\text { error }\end{array}$ & Significance \\
\hline \multicolumn{5}{|l|}{$\overline{\text { Self-esteem } \rightarrow}$} \\
\hline $\begin{array}{l}\text { Expectations of complexity } \\
\text { Capabilities } \longrightarrow\end{array}$ & .08 & .02 & .02 & .37 \\
\hline Expectations of complexity & & -.61 & .14 & .00 \\
\hline \multirow[t]{2}{*}{ Expectations of complexity } & -.48 & .85 & .85 & .02 \\
\hline & Covariances & \multicolumn{2}{|c|}{ Standard error } & Significance \\
\hline Capabilities $\longleftrightarrow$ & & & & \\
\hline $\begin{array}{l}\text { Product knowledge } \\
\text { SEC } \leftrightarrow\end{array}$ & .23 & .08 & & .00 \\
\hline $\begin{array}{l}\text { Product knowledge } \\
\text { SEC } \leftrightarrow\end{array}$ & .33 & .11 & & .00 \\
\hline $\begin{array}{l}\text { Capabilities } \\
\text { Product knowledge } \leftrightarrow\end{array}$ & 1.20 & .15 & & .00 \\
\hline $\begin{array}{l}\text { Self-esteem } \\
\text { Capabilities } \longleftrightarrow\end{array}$ & 1.15 & .40 & & .00 \\
\hline $\begin{array}{l}\text { Self-esteem } \\
\text { SEC } \leftrightarrow\end{array}$ & 6.06 & .78 & & .00 \\
\hline Self-esteem & 6.30 & .73 & & .00 \\
\hline
\end{tabular}

Goodness of fit $\chi^{2}=259.7, d f=157, p<.00 ; \mathrm{CFI}=.965 ;$ RMSEA $=.050 ; \mathrm{TLI}=.953$.
Table 5

Estimates for the measurement model.

\begin{tabular}{|c|c|c|c|c|}
\hline $\begin{array}{l}\text { Measurement } \\
\text { model }\end{array}$ & $\begin{array}{l}\text { Standardized } \\
\text { coefficients }\end{array}$ & $\begin{array}{l}\text { Unstandardized } \\
\text { coefficients }\end{array}$ & $\begin{array}{l}\text { Standard } \\
\text { error }\end{array}$ & Significance \\
\hline \multicolumn{5}{|l|}{ Socioeconomic class } \\
\hline Educational scale $^{a}$ & .48 & 1.00 & & NA \\
\hline Residential area & .44 & 1.01 & .06 & .00 \\
\hline Monthly income & .34 & .80 & .07 & .00 \\
\hline Parents' educational scale & .44 & 1.02 & .06 & .00 \\
\hline \multicolumn{5}{|l|}{ Self-esteem } \\
\hline General $^{\mathrm{a}}$ & .60 & 1.00 & & NA \\
\hline School & .39 & .26 & .04 & .00 \\
\hline Peers & .34 & .23 & .03 & .00 \\
\hline Home & .43 & .40 & .05 & .00 \\
\hline \multicolumn{5}{|l|}{ Product knowledge } \\
\hline PDA knowledge & .78 & 4.73 & 1.40 & .00 \\
\hline E-book reader knowledge ${ }^{a}$ & .23 & 1.00 & & NA \\
\hline \multicolumn{5}{|l|}{ Capabilities } \\
\hline Spatial intelligence $^{\mathrm{a}}$ & .65 & 1.00 & & NA \\
\hline Linguistic ability & .67 & .89 & .09 & .00 \\
\hline Arithmetic ability & .71 & 1.18 & .12 & .00 \\
\hline Verbal fluency & .66 & .97 & .10 & .00 \\
\hline Interpersonal intelligence & .40 & .43 & .07 & .00 \\
\hline \multicolumn{5}{|l|}{ Expectations of complexity } \\
\hline Product challenge $^{a}$ & .79 & 1.00 & & NA \\
\hline Product learning time & .84 & 1.01 & .09 & .00 \\
\hline Product difficulty & .70 & .90 & .09 & .00 \\
\hline Task challenge & .81 & .98 & .08 & .00 \\
\hline Task learning time & .79 & 1.01 & .08 & .00 \\
\hline Task difficulty & .75 & .94 & .08 & .00 \\
\hline
\end{tabular}

a Loading value fixed at 1.00 for estimation purposes.

\subsection{Managerial implications}

The managerial implications of this research are primarily to companies and organizations that are marketing products and services to subsistence consumers. Marketers of new technology products currently try to address income and literacy barriers to adoption through cost reductions and educational actions, respectively. Those are strategies that aim to bring the subsistence consumer closer to the requirements of the new product. The barriers to product adoption identified in this research, however, pose a different challenge. Two of the beliefs that cause complexity expectations and stand in the way of new product adoption among subsistence consumers are about the self. Am I worthy enough to understand and use this product? Do I have the skills required? Strategies aimed at directly modifying consumer selfesteem and self-assessed capabilities might be costly and difficult to implement, although assurances to consumers about their worth and capability to purchase and use new product technologies through promotional messages certainly seem appropriate. Strategies aimed at improving consumer knowledge of product domains could be more effective, but commercially viable results may take a considerable amount of time to emerge. One possible approach to subsistence consumers in the face of these factors is to implement adaptive strategies.

One possibility is to develop a more nuanced and detailed segmentation, identifying within the greater subsistence consumer segment potential adopters that may be more or less difficult to persuade. Younger consumers, for example, by virtue of being exposed to more media and information in school, may hold greater product knowledge or see themselves as more capable than older subsistence consumers. Gender differences are also possible, where men may be more exposed to product domains than women by virtue of working outside the home and hold more product knowledge, while women may spend more time sharing information in their local communities and see themselves as more capable to adopt at least some new technologies. Another adaptive strategy may be to develop finely 
tailored marketing communications aimed at counteracting the negative influences on adoption that can emerge from living in a subsistence socioeconomic context. In either case, the research suggests that marketers may only need to rely on socioeconomic class and some additional demographic variables to develop and implement their segment strategies because of the over-representation of low product knowledge, low self-esteem, and low self-assessed capabilities among subsistence consumer. Explicit tactics should be implemented to reduce complexity expectations by incorporating knowledge, self-esteem and subjective capabilities as the key strategic targets for interventions.

\subsection{Limitations and future research}

The relationships established in this research were tested using an information technology-rich new product (a digital book), and extending the findings to product categories that do not involve such complex technologies may be challenging. For instance, innovations on services or financial products involve a different type and level of interaction between the consumer and the product, and additional factors such as reliance on service providers may also contribute to expectations of complexity. Moreover, self-esteem and self-assessed capabilities may be vulnerable to human interaction factors (e.g., service provider attractiveness and tone of voice) that have nothing to do with the consumption process but may at the point of adoption elevate expectations of complexity by altering self-esteem and self-assessed capabilities. The tested framework must be expanded and altered for application to other types of products.

Another limitation is the sampling. Although Bogotá is economically and demographically similar to large urban areas in other emerging economies, unique cultural factors may be affecting the results. One possibility is that subsistence consumers in Bogotá are more comfortable fighting against stereotypes attached to socioeconomic class by virtue of slightly higher levels of individualism than would be found in other cultures (Hofstede, 1984), a factor that would attenuate the influence of socioeconomic class on self-esteem and self-assessed capabilities. Cultural influences could in turn change how self-esteem and self-assessed capabilities affect expectations of complexity. Further research into the interaction of culture with socioeconomic class is needed.

Finally, the data come from a quasi-experimental procedure conducted in a neutral and artificial setting. Although participants were recruited directly from their neighborhoods, they interacted with the stimulus in isolation, and in an unfamiliar environment, a situation that prevented them from engaging in social interactions that may be common in their neighborhoods, and which may affect their expectations of complexity. The results stand as a test of how individual level factors influence complexity expectations in single-shopper experiences. Research into the influence of socioeconomic class and related variables on product complexity expectations in other settings is recommended.

\section{Acknowledgement}

The authors thank two anonymous reviewers, Madhu Viswanathan, participants of the 2008 Subsistence Marketplaces conference (University of Illinois at Chicago) and members of the marketing research group at Universidad de los Andes - School of Management (UASM) for useful comments, and the UASM's research committee for financial support.

\section{Appendix A}

\section{Appendix A.1. Bogotá's utilities stratification scheme}

Bogotá has a population of 7,215,234 inhabitants. Authorities classify the residential areas in six strata. Such classification is based on housing characteristics. This was established to accomplish three main objectives: First, to distribute utility subsidies to subsistence (low strata) consumers. Second, to facilitate the design and administration of social programs through the existence of a single identifier of eligibility or need. Finally, it is used to determine set property taxes. Inclusion of residential stratum as a component of socioeconomic class expands the metric for this research to encompass consumer characteristics (e.g., education, income) and market context.

\section{Appendix A.2. Questions used to gather socioeconomic class indicators}

Educational level ${ }^{1}$ : None ___Elementary School___ High School__ Technical Education___ College__ Graduate School __

Residential area: $1 \_2 \_3 \_4 \_5 \_6 \_$

Household monthly income: Less than US\$180_ between US $\$ 181$ and US\$400_ between US\$401 and US\$800_ between US $\$ 801$ and US\$1400_ between US\$1401 and US\$2000_ more than US\$2000

Father educational level: None __ Elementary School__ High School __ Technical Education___ College__ Graduate School __

Mother educational level: None __ Elementary School__ High School __ Technical Education__ College__ Graduate School __

\section{References}

Adkins Natalie R, Ozanne Julie L. The low literate consumer. J Consum Res 2005;32 (1):93-105.

Al-Gahtani Said S. Computer technology adoption in Saudi Arabia: correlates of perceived innovation attributes. Inf Technol Dev 2003;10(1):57-69.

Alwitt Linda F, Donley Thomas D. The low-income consumer: adjusting the balance of exchange. London: Sage Publications; 1996.

Bandura Albert. Regulation of cognitive processes through perceived self-efficacy. Dev Psychol 1989;25(5):729-35.

Bandura Albert. Self-efficacy: the exercise of control. New York: W.H. Freeman; 1997.

Bauman Zygmunt. Work, consumerism and the new poor. Buckingham: Open University Press; 1988.

Becker Saul. Responding to poverty: the politics of cash and care. London: Longman; 1997.

Beloff Halla. Mother, father and me: our IQ. The Psychologist 1992;5:309-11.

Bettman James R, Park Whan. Effects of prior knowledge and experience and phase of the choice process on consumer decision processes: a protocol analysis. J Consum Res 1980; 7:234-48 (December).

Blascovich J, Tomaka J. Measures of self-esteem. In: Robinson, Shaver, Wrightsman, editors. Measures of personality and social psychological attitudes. San Diego, CA: Academic Press; 1991. p. 115-60.

Boardman Jason D, Robert Stephanie A. Neighborhood socioeconomic status and perceptions of self-efficacy. Sociol Perspect 2000;43(1):117-36.

Boyce Gordon. Valuing customers and loyalty: the rhetoric of consumer focus versus the reality of alienation and exclusion of (devaluated) customers. Crit Perspect Account 2000;11(6):649-89.

Browne Michael, Robert Cudeck. Alternative ways of assessing model fit. In: Kenneth, Scott, editors. Testing structural equation models. Sage Focus Editions; 1993. p. 136-59.

Bruner Gordon, Kumar Anand. Explaining consumer acceptance of handheld internet devices. J Bus Res 2005;58:553-8.

Carmines Edward, Mclver John. Analyzing models with unobserved variables: analysis of covariance structures. In: Bohrnstedt Borgotta, editor. Social measurement: current issues. Beverly Hills, CA: Sage; 1981. p. 65-115.

Coleman Richard. The continuing significance of social class to marketing. J Consum Res 1983;10(3):265-80.

Coopersmith Stanley. The antecedents of self-esteem. NY: Freeman Press; 1967.

Crocker Jennifer, Major Brenda. Social stigma and self-esteem: the self-protective properties of stigma. Psychol Rev 1989;96:608-30.

Croizet Jean-Claude, Claire Theresa. Extending the concept of stereotype threat to social class: the intellectual underperformance of students from low socioeconomic backgrounds. Pers Soc Psychol Bull 1998;24:588-94 (June).

Davis Ian, Stephenson Elizabeth. Ten trends to watch. The McKinsey Quarterly January. McKinsey \& Company (electronic resource; 2006.

Davis Fred, Bagozzi Richard, Warshaw Paul. User acceptance of computer technology: a comparison of two theoretical models. Manag Sci 1989;35:982-1003 (August).

Gardner Howard. Frames of mind: the theory of multiple intelligences. NY: Basics; 1983.

\footnotetext{
${ }^{1}$ The Exchange rate is 1 Dollar $=2506$ Colombian pesos (January 2009)
} 
Gist Marilyn, Mitchell Terence. Self-efficacy: a theoretical analysis of its determinants and malleability. Acad Manag Rev 1992;17(2):183-211.

Gregan-Paxton Jennifer. How does prior knowledge influence consumer learning? A study of analogy and categorization effects. Working paper, Department of Business Administration, University of Delaware, Newark; 1999.

Gregan-Paxton Jennifer, John Deborah. Consumer learning by analogy: a model of internal knowledge transfer. J Consum Res 1997;24:266-84 (December).

Hair Joseph, Anderson Rolph, Tatham Ronald, Black William. Multivariate data analysis. NJ: Prentice Hall; 1998.

Hall Rosalie, Snell Andrea, Singer Foust Michelle. Item parceling strategies in SEM: investigating the subtle effects of unmodeled secondary constructs. Organ Res Methods 1999;2(3):233-56.

Hamilton Kathy, Catterall Miriam. Towards a better understanding of the low-income consumer. Adv Consum Res 2005;32:627-32.

Hammond, Allen L., Kramer, William J., Katz, Robert S., Tran, Julia T., Walker, Courtland, 2007. The next four billion: market size and business strategy at the base of the pyramid. Washington, DC: World Resources Institute, International Finance Corporation.

Hanson Margaret, Powell Karen. Procter \& Gamble PuR: purifier of water. INSEAD; 2006

Hill RonaldP, Gaines Jeannie. The consumer culture of poverty: behavioral research findings and their implications in an ethnographic context. J Am Cult 2007;30:81-95 (March).

Hill RonaldP, Stephens Debra. Impoverished consumers and consumer behavior: the case of AFDC mothers. J Macromark 1997;19:32-48 (December).

Hofstede Geert. Culture's consequences: international differences in work-related values. Beverly Hills, CA: Sage Publications; 1984

Hollingshead August, Redlich Frederick. Social class and mental illness: a community study. NY: John Wiley; 1967.

Hu Li-Tze, Bentler PeterM. Cutoff criteria for fit indexes in covariance structure analysis: conventional criteria versus new alternatives. Struct Equ Modeling 1999;6(1):1-55.

Johar Gait, Jedidi Camel, Jacoby Jacob. A varying parameter averaging model of on-line brand evaluations. J Consum Res 1997;24:232-48 (September).

Jones Rachel, Ye Lou. The culture of poverty and African American culture: an empirica assessment. Sociol Perspect 1999;42:439-59.

Kulviwat Songpol, Bruner II GordonC, Kumar Anand, Nasco SuzanneA, Clark Terry. Toward a unified theory of consumer acceptance technology. Psychol Mark 2007;24 (12):1059-84

Lara-Cantú MaríaAsunción, Verduzco MaríaAngélica, Acevedo Maricarmen, Cortés José. Validez y confiabilidad del inventario de autoestima de Coopersmith para adultos, en población mexicana. Rev Latinoam Psicol 1993;25:247-55.

Levy Sidney. Social class and consumer behavior. In: Newman J, editor. On knowing the consumer. NY: John Wiley; 1966. p. 146-60.

Lewis O. Five families: Mexican case studies in the culture of poverty. NY: Basic Books 1959.

Marsh HerbertW, Hau Kit-Tai, Wen Zhonglin. In search of golden rules: comment on hypothesis-testing approaches to setting cutoff values for fit indexes and dangers in overgeneralizing Hu and Bentler's (1999) findings. Struct Equ Modeling 2004;11 (3):320-41.

McCracken Grant. Culture and consumption: a theoretical account of the structure and movement of the cultural meaning of consumer goods. J Consum Res 1986;13:71-84 (June).

Medina Martin. The world's scavengers: salvaging for sustainable consumption and production. Lanham, MD: AltaMira Press; 2007.
Moreau Page, Lehmann Donald, Markman Arthur. Entrenched knowledge structures and consumer response to new products. J Mark Res 2001a;38:14-29 (February).

Moreau Page, Markman Arthur, Lehmann Donald. What is it? Categorization flexibility and consumers' responses to really new products. J Consum Res 2001b;27:489-98 (March).

Oliver Richard, Winter Russell. A framework for the formation and structure of consumer expectations: review and propositions. J Econ Psychol 1987;8(4):469-99.

Prahalad CK. The fortune at the bottom of the pyramid: eradicating poverty through profits. Upper Saddle River, NJ: Wharton School Publishing; 2005.

Rammstedt Beatrice, Rammsayer ThomasH. Self-estimated intelligence: gender differences, relationship to psychometric intelligence and moderating effects of level of education. Eur Psychol 2002;7:275-84 (December).

Rist R. Students social class and teacher expectations: the self-fulfilling prophecy in ghetto education. Harv Educ Rev 1970;40:411-51.

Rogers Everett. Diffusion of innovations. NY: The Free Press; 1996.

Schaninger Charles. Social class versus income: an empirical investigation. J Mark Res 1981;18:192-208 (May).

Shih Chuan-Fong, Venkatesh Alladi. Beyond adoption: development and application of a use-diffusion model. J Mark 2004;68:59-72 (January).

Sridharan, Srinivas, Viswanathan, Madhubalan. Marketing in subsistence marketplaces: consumption and entrepreneurship in a South Indian context. J Consum Mark 2008;25 (7):455-62.

Steele C. A threat in the air: how stereotypes shape the intellectual identities and performance of women and African Americans. Am Psychol 1997;52:613-29.

Thompson Debora, Hamilton Rebecca, Rust Roland. Feature fatigue: when product capabilities become too much of a good thing. J Mark Res 2005;42:431-42 (November).

Tornatzky Louis, Klein Katherine. Innovation characteristics and innovation adoptionimplementation: a meta-analysis of findings. IEEE Trans Eng Manage 1982;29(1):28-43.

Twenge Jean, Campbell Keith. Self-esteem and socioeconomic status: a meta-analytic review. Pers Soc Psychol Rev 2002;6(1):59-71.

Venkatesh Viswanath, Davis Fred, Morris Michael. Dead or alive? The development, trajectory and future of technology adoption research. J Assoc Inf Syst 2007;8:268-86 (April).

Viswanathan Madhubalan. Measurement error and research design. Sage: London; 2005.

Viswanathan, Madhubalan, Rosa, José Antonio, 2007. Product and market development for subsistence marketplaces: consumption and entrepreneurship beyond literacy and resource barriers. In: Rosa José and Viswanathan Madhubalan, Volume editors. Advances in International Management Series, vol. 20. Oxford: Elsevier. pp. 1-17.

Viswanathan Madhubalan, Gajendiran S, Venkatesan R. Enabling consumer and entrpreneurial literacy in subsistence marketplaces. New York: Springer; 2008.

Weidner Kelly, Rosa José Antonio, Viswanathan Madhubalan. Marketing to subsistence consumers: lessons from practice. J Bus Res 2010;63:559-69 (this issue).

Wheatley John J, Chiu JohnS, Stevens AndreaC. Demographics to predict consumption. J Advert Res 1980;20:31-8 (December).

Wood StacyL, Moreau CPage. From fear to loathing? How emotions influence the evaluation and early use of innovations. J Mark 2006;70:44-57 (July).

Yamauchi Takashi, Markman Arthur. Inference using categories. J Exp Psychol Learn Mem Cogn 2000;26:776-95 (May).

Zukin Sharon, Maguire Jennifer. Consumer and consumption. Ann Rev Sociology 2004;30:173-97. 